\title{
Staging of Mental Disorders: Systematic Review
}

\author{
Fiammetta Cosci ${ }^{a} \quad$ Giovanni A. Fava ${ }^{b, c}$ \\ a Department of Psychology, University of Florence, Florence, and ${ }^{b}$ Department of Psychology, University of \\ Bologna, Bologna, Italy; ' Department of Psychiatry, State University of New York at Buffalo, Buffalo, N.Y., USA
}

\section{Key Words}

Systematic review $\cdot$ Staging $\cdot$ Mental disorder $\cdot$ Psychiatric disorder $\cdot$ Clinimetrics $\cdot$ Anxiety $\cdot$ Mood disorders •

Schizophrenia $\cdot$ Eating disorders $\cdot$ Substance abuse

\begin{abstract}
Background: The staging method, whereby a disorder is characterized according to its seriousness, extension, development and features, is attracting increasing attention in clinical psychology and psychiatry. The aim of this systematic review was to critically summarize the tools that are available for reproducing and standardizing the clinical intuitions that are involved in a staging formulation. Methods: A comprehensive research was conducted on the MEDLINE, PsycINFO, EMBASE and Cochrane databases from inception to May 2012. The following search terms were used: 'stage/ staging' AND 'psychiatric disorder/mental disorder/schizophrenia/mood disorder/anxiety disorder/substance use disorder/eating disorder'. Results: A total of 78 studies were identified for inclusion in the review. We discussed studies addressing or related to the issue of staging in a number of mental disorders (schizophrenia, unipolar depression, bipolar disorder, panic disorder, substance use disorders, anorexia and bulimia nervosa). The literature indicates that disorders have a longitudinal development or a treatment history that can be categorized according to stages. We proposed staging formulations for the above-mentioned psychiatric
\end{abstract}

disorders. Conclusion: Staging models offer innovative assessment tools for clinical psychologists and psychiatrists. Characterizing each stage of an illness demarcates major prognostic and therapeutic differences among patients who otherwise seem to be deceptively similar since they share the same psychiatric diagnosis. A stage 0 to denote an at-risk condition does not appear to be warranted at the current state of research.

Copyright $\odot 2012$ S. Karger AG, Basel

\section{Introduction}

Psychiatric diagnosis has attracted prominent attention in clinical psychology and psychiatry. The introduction of diagnostic criteria for the identification of psychiatric syndromes, such as the Diagnostic and Statistical Manual of Mental Disorders (DSM) [1], has considerably decreased the variance due to different assessors and the use of inferential criteria rather than direct observation. However, there is increasing awareness of the limitations of the current diagnostic systems and concern about future DSM or International Classification of Diseases [2] developments [3-5]. The customary clinical taxonomy in psychiatry does not include, for instance, patterns of symptoms, severity of illness or effects of comorbid conditions that demarcate major prognostic and therapeutic differences among patients who otherwise seem to be de-

\section{KARGER \\ Fax +4161306 1234 \\ E-Mail karger@karger.ch}

www.karger.com

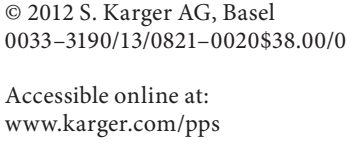

Dr. Fiammetta Cosci

Department of Psychology, University of Florence

Via di San Salvi 12

IT-50135 Florence (Italy)

E-Mail fiammetta.cosci@unifi.it 
ceptively similar since they share the same psychiatric diagnosis [6]. Such specifications pertain to the concept of clinimetrics [7], which indicates a domain concerned with indexes, rating scales and other expressions used to describe or measure symptoms, physical signs and other distinctly clinical phenomena $[8,9]$.

The use of diagnostic criteria in clinical psychology and psychiatry is derived from the traditional method of clinical medicine in which the use of diagnostic criteria provides operating specifications for making a clinical decision about the existence of a particular disease. If a disease is defined morphologically, the criteria contain specifications for making a clinical diagnosis when the definitive morphological evidence is not available. If a disease is not defined morphologically, the criteria can serve both to define the disease and to provide specifications for its diagnosis. The latter use is prevalent in clinical psychology and psychiatry.

However, there is another common and complementary method of classifying medical disorders, namely staging. Once an index identifies the existence of a particular disease state, there is often a clinical need to rate its seriousness, extent and characteristics. An example is provided by the New York Heart Association Functional Classification [10], which ranges from class I, i.e. patients with cardiac disease without resulting limitations of physical activity, to class IV, i.e. patients with cardiac disease with severe physical activity limitations. Staging has also assumed paramount importance in clinical oncology, in which the stage of the disease often determines the choice of treatment and indicates the prognosis. One of the methods is the Ann Arbor staging classification of lymphomas [11], in which the clinical stage is defined by the apparent extent of disease based on physical and instrumental examination.

Notwithstanding the long tradition of staging in developmental psychology [12, 13], clinical psychology and psychiatry had for a long time neglected staging as a model to classify the development of mental disorders. This neglect has paralleled the reliance on cross-sectional descriptions instead of longitudinal study of prodromes, the fully developed disorder and residual phase [14].

In 1993, Fava and Kellner [15] introduced the clinimetric concept of staging in psychiatric classification. They developed staging methods for unipolar depression, bipolar disorder, panic disorder and schizophrenia based on the longitudinal development of a psychiatric disorder, ranging from the prodromal to the residual and chronic forms. In the past decade there have been further developments in the literature [16-24]. Such contribu- tions have stressed the role of staging to improve the clinician's capacity to select treatments relevant to earlier stages, assuming that these interventions can be more effective and less harmful than treatments delivered later in the course of the illness and that they might help prevent progression to more advanced stages or promote regression to an earlier stage. In this framework, it has been proposed to develop ground rules for clarifying which people are at risk of mental illness and what sequence of established and novel or experimental therapeutic strategies is most likely to successfully achieve remission and psychosocial recovery and reduce the risk of persistence and recurrence.

To the best of our knowledge, there has not been a systematic review attempting to synthesize the different models of staging currently known in clinical psychology and psychiatry in order to update and expand the work of Fava and Kellner [15]. We will not specifically review the studies describing prodromal and/or residual symptomatology in the longitudinal development of disorders, but we will mention their potential relevance to the construction of staging systems.

\section{Methods}

Eligibility Criteria

Eligible articles included English-language papers published in peer-reviewed journals reporting data on adult subjects with psychiatric disorders according to the DSM-III, -IIIR, -IV or -IVTR, the Research Diagnostic Criteria [25] or the International Classification of Diseases. A further inclusion criterion for articles on staging models was that they had to propose a complete staging model. Further inclusion criteria for articles on clinical features were as follows: no additional co-occurring psychiatric disorders (either Axis I or Axis II) or organic disease and inclusion of at least 10 patients. Additional inclusion criteria for articles on treatment interventions were those chosen for articles on clinical features plus the following: inclusion of a comparison group or a crossover design, and a double-blind design in the case of pharmacological treatments or at least a single-blind design in the case of nonpharmacological treatments.

Papers dealing exclusively with neuroanatomy or biological markers were not included since this review was focused on staging models, their clinical features and treatment implications.

\section{Information Sources and Searches}

The MEDLINE, PsycINFO, EMBASE and Cochrane databases were systematically searched from inception to May 2012. In addition, a manual search was performed of reference lists from all articles selected, for full-text reviews and relevant reviews.

The search terms were 'stage/staging', combined using the Boolean 'AND' operator with 'psychiatric disorder/mental disorder/schizophrenia/mood disorder/anxiety disorder/substance use disorder/eating disorder'. In the online supplementary appen- 
dix (see www.karger.com/doi/10.1159/000342243 for all online suppl. material), we report the search strategy used for MEDLINE.

Titles and abstracts were screened by one reviewer (F.C.). Articles that appeared potentially relevant were retrieved, and two reviewers (F.C. and G.A.F.) independently assessed each of the full reports, arriving at a consensus regarding eligibility. For each excluded study, we determined which elements of the electronic search were not addressed.

When information about the methods or results was omitted, the writers of the report were contacted to obtain the missing information. If duplicate publications were suspected, the authors of the reports were contacted to receive further details. If duplicate publication was confirmed, only the report with the largest sample size was included.

To ascertain the validity of eligible studies, two investigators independently rated each study on the basis of the following markers: (1) in the case of studies on staging models, presentation of a complete model with motivation of its existence; (2) in the case of studies on clinical features, homogeneity of samples with regard to the diagnosis and age (equal to or greater than 18 years), and (3) in the case of studies testing treatments, homogeneity of samples with regard to the diagnosis and age (equal to or greater than 18 years), inclusion of a comparison group, appropriate random allocation, blinding of participants, proportion of patients lost to follow-up and stopping of trials early for benefit.

Any disagreements were resolved by consensus.

The search strings and the list of relevant reviews that were used with the literature search, the data coding and the quality criteria that were used can be requested from the corresponding author

The methods described here fulfilled Preferred Reporting Items for Systematic Reviews and Meta-Analyses guidelines [26].

\section{Results}

\section{Selection of Articles and Study Characteristics}

A total of 78 studies (32 on staging models, 27 on clinical features and 19 on treatment) were identified for inclusion in the review. The search of MEDLINE, PsycINFO, EMBASE and Cochrane databases provided a total of 17,789 citations. After adjusting for duplicates and reviewing the abstracts to exclude those which clearly did not meet the criteria, 362 remained. Of these, 281 studies were discarded because they did not meet the inclusion criteria. Three additional studies were discarded because the full text of the paper was not available. No unpublished relevant studies were obtained (online suppl. fig. 1).

\section{Schizophrenia}

A first staging model of schizophrenia was proposed by Fava and Kellner [15], as follows: prodromal symptoms (mainly affective and negative symptoms), with deterioration of functioning, represented stage 1 ; the acute epi- sode was stage 2 ; residual symptoms were stage 3 ; subchronic symptoms (i.e. lasting less than 2 years but more than 6 months) occurred at stage 4, and chronic symptoms (i.e. lasting more than 2 years) were stage 5 .

In 2001, Lieberman et al. [27] proposed a model that was only slightly different, with the inclusion of a premorbid stage and the existence of a chronic and a residual phase of illness at the same stage of the model.

Subsequently, McGorry and coworkers proposed another version that underwent various updates [19-23]. Stage 0 was represented by an increased risk of psychotic (or severe mood) disorder although there were no current symptoms. At stage 1a, there were mild or nonspecific symptoms. At stage $1 \mathrm{~b}$, subjects presented moderate subthreshold symptoms. At stage 2, there was the onset of the first episode of psychosis (or severe mood disorder mania or depression). At stage 3a, an incomplete remission from the first episode of care occurred. Stage $3 b$ included recurrence or relapse of psychotic (or mood) disorder. Multiple relapses, when worsening in clinical extent and the impact of illness, were objectively present at stage 3c. Stage 4 referred to severe, persistent or unremitting illness.

Recently, Agius et al. [28] proposed 3 stages in the development of schizophrenia which differ only slightly from those of Fava and Kellner [15]. In the first stage, that is the prodrome phase, there is a loss of gray matter as well as changes in cognition which develop as the illness develops. The second stage is characterized by the first episode of illness and progressive cognitive decline. At stage 3 , schizophrenia was chronic, and disruptions in neurodevelopment or neural plasticity occurred.

On the basis of the above literature, we here propose a staging model for schizophrenia with the aim of mediating and integrating those mentioned above (table 1). This model, as well as all the other ones suggested here, is based on the basic steps of a psychiatric disorder, ranging from the prodromal to the residual/chronic form, in a longitudinal view of development of disturbances [6], and finds support in the current literature. Since more detailed models that may yield therapeutic interventions in a preacute phase do not find adequate support from the literature and need specific clinical validation, stage 0 was not taken into account. In fact, prodromal symptoms, which characterize stage 1 , can be appraised only retrospectively, and their predictive power in the general population is very limited [29-32] because of their nonspecific features. Residual symptoms at stage 3 are also nonspecific. Depression [30,33], trouble concentrating [30], trouble sleeping [30], being 
Table 1. Staging of schizophrenia

\begin{tabular}{ll}
\hline Stage 1 & prodromal phase with deterioration of functioning \\
\hline Stage 2 & acute manifestations \\
\hline Stage 3 & residual phase \\
\hline Stage 4 & chronic phase (in attenuated or persistent form) \\
\hline
\end{tabular}

Table 2. Staging of unipolar depression

\begin{tabular}{ll}
\hline Stage 1 & $\begin{array}{l}\text { prodromal phase } \\
\text { a }\end{array}$ \\
& no depressive symptoms (generalized anxiety, \\
& irritability, anhedonia, sleep disorders) with mild \\
& bunctional change or decline \\
& mood symptoms (sad mood, subsyndromal \\
& depression)
\end{tabular}

tense and nervous, restlessness and loss of interest [33] are common.

Many opinion papers on the treatment of specific stages of illness have been published. For instance, Lieberman et al. [27] proposed no treatments at the premorbid and prodromal stage, antipsychotic drugs for the acute phase and antipsychotics, although having limited efficacy, for the chronic/residual stage. However, the evidence to support these decisions is really limited. One study showed that the likelihood of successful resolution of a prodrome increased over time under fluphenazine compared to placebo [34]. Herz et al. [35] found that a program for relapse prevention was more effective than treatment as usual in reducing relapse and rehospitalization rates among schizophrenic outpatients. Another study, comparing integrated psychological intervention and supportive counseling administered at the early initial prodromal stage to prevent psychosis, showed that the first was superior to the second at the 12- and 24-month follow-up [36].

\section{Unipolar Depression}

Fava and Kellner [15] described a staging model of unipolar depression that was updated in 2007 [37]. The prodromal phase was characterized by the onset of depressive symptoms, mainly anxiety, irritable mood, anhedonia and sleep disorders. At stage 2, subjects suffered a major depressive episode, then a residual phase (stage 3) may occur with no depressive symptoms or with dysthymia. Stage 4 was characterized by recurrent depression or double depression, while at stage 5 , subjects had a chronic major depressive episode lasting at least 2 years without interruptions.

In 2008, Hetrick et al. [38] suggested a similar staging model; however, their model did not include dysthymia and referred to neurocognition and disability.

We here propose an updated version of the Fava and Tossani [37] model (table 2).

Generalized anxiety and irritability seem to be the most common prodromes of unipolar depression. Other symptoms which can characterize stage 1 are impaired activities [39], depressed mood [39], guilt, anorexia [39], fatigue and initial and delayed insomnia. Prodromes increase the risk of the occurrence of major depression [40, $41]$, are quite similar to residual symptoms [42, 43] and can be the front door to relapse [44-46]. This parallels the fact that patients with 'double depression' are less likely to recover and more likely to relapse [37]. Residual symptoms may occur at stage 3 . They frequently mirror the prodromal stage [44]. Decreased somatic anxiety, increased psychological anxiety, appetite, libido or hypochondriasis were found to be predictors of relapse/recurrence in patients who responded to acute-phase continuation-phase cognitive therapy [47].

A strong relationship between prodromal and residual symptoms has been substantiated since almost $70 \%$ of residual symptoms are present in the prodromal phase of the illness [42]. Similarly, the link between dysthymia and a relapse of unipolar depression has been widely confirmed. Klein et al. [48] observed that about $74 \%$ of patients with dysthymic disorder who recovered from a major depressive episode for the second time experienced another relapse into depression, for an estimated relapse rate of $93.2 \%$. In addition, about $24 \%$ of dysthymic disorder patients who had recovered had a relapse into chronic depression [49].

In two randomized controlled trials [50, 51], psychotherapeutic intervention was applied according to the staging method developed by Fava and Kellner [15] and was found to yield long-term benefits. Patients with major depressive disorder successfully treated with antide-

Psychother Psychosom 2013;82:20-34 
pressant drugs were randomly assigned to cognitive behavioral treatment (CBT) or clinical management of residual symptoms. The group that received CBT had a significantly lower level of residual symptoms in comparison with the clinical management group. CBT also resulted in a lower rate of relapse at 2-6 years of followup. This approach was then validated by other randomized controlled trials, in which cognitive behavioral strategies applied to remitted patients were found to improve the long-term outcome of major depression compared to clinical management or treatment as usual [52].

Several efforts have also been made to develop methods to stage the degree of treatment resistance in patients with unipolar depression. Thase and Rush [53] proposed a 5-stage model (TR-S) that yields a categorical assignment of degree of resistance. Patients were classified according to the number and classes of antidepressants that failed to produce a response, with staging moving from more common to less common treatments. Thus, for instance, stage I was characterized by failure of at least 1 adequate trial of 1 major class of antidepressant.

According to a second model, called the European approach [54], stage A represented no response to 1 adequate antidepressant trial lasting 6-8 weeks; treatmentrefractory depression, stage $B$, was the failure of 2 or more adequate trials of different antidepressants given in adequate dosages for a period of at least 12-16 weeks but no longer than 1 year, and chronic resistant depression (stage C) was characterized as resistance to several antidepressant trials, including augmentation strategy, lasting 12 months or more. This was in contrast to the TR-S, which referred to resistance as the failure of at least 1 adequate trial. Additionally, Souery et al. [54] proposed a condition called chronic resistant depression.

A group from the Massachusetts General Hospital formulated a slightly different approach that considers both the number of failed trials and the intensity or optimization of each trial without assumptions regarding the hierarchy of antidepressant classes. This method generated a continuous variable reflecting the degree of resistance in depression and ranging from 0 to 5 [55].

The limitations of the three models were described by Berlim and Turecki [56]. The TR-S lacked exploration of the degree of dosing/duration of treatment, assumed that nonresponse to 2 agents of different classes is more difficult to treat than nonresponse to 2 agents of the same class and made an implicit hierarchy of treatments not accounting for the role of augmentation and combination strategies. With reference to the European criteria, the duration of adequate trials and the distinction between treatment-refractory depression and chronic resistant depression were arbitrarily chosen. The model from the Massachusetts General Hospital was based on limited data reliability and scores attributed arbitrarily to each treatment.

The Massachusetts General Hospital Staging Method and the TR-S have been tested as predictors of remission status. According to Petersen et al. [57], the Massachusetts General Hospital Staging Method demonstrated significantly greater ability to predict nonremission than the TR-S. This study has been criticized for the relatively small sample size, the use of chart review methodology and the probable nongeneralizability of the findings to other populations [56].

More recently, a multidimensional staging model, the Maudsley Staging Method, was proposed [58, 59]. In addition to the number of failed treatment trials, it incorporated factors considered to be closely related to the depressive illness itself, namely the duration and severity of the illness, treatment failure with antidepressants, use of augmentation and use of electroconvulsive therapy. In the end, the stage of treatment resistance was represented as a single score ranging from 3 to 15 .

An attempt to integrate the four models is proposed in table 3. The basic principle is that it is quite different to treat a patient with a major depressive episode who displayed a positive response to previous therapeutic trials (stage 0 ) and a patient who failed to respond to various adequate trials, including one involving augmentation/ combination (stage 4) [6]. In our model, the expression 'therapeutic' means either psychopharmacological therapy or psychotherapy.

Classifying the treatment response of each patient can shed some light on whether long-term treatment with antidepressive agents may increase susceptibility to subsequent episodes [60] or lead to tardive dysphoria [61] or supersensitivity phenomena [62] and on the mechanisms of loss of clinical response during long-term antidepressant treatment [60].

\section{Bipolar Disorder}

Carlson and Goodwin [63] described how inpatients with mania go through 3 different stages. The initial phase is characterized by somewhat pressured speech, elation and hyperactivity. The second stage is characterized by paranoid, hypertalkative and grandiose features. The final stage involves delusions, sexual worries, lability and anger [63]. Later on, Fava and Kellner [15] referred to a staging model of mania with the following 4 phases: (1) prodromal (i.e. increased self-confidence, energy and 
Table 3. Staging of levels of treatment resistance of unipolar depression

\begin{tabular}{ll}
\hline Stage 0 & no history of failure to respond to therapeutic trial \\
\hline Stage 1 & $\begin{array}{l}\text { failure of at least } 1 \text { adequate therapeutic trial } \\
\text { duration of trial: } 6-8 \text { weeks }\end{array}$ \\
\hline Stage 2 & $\begin{array}{l}\text { failure of at least } 2 \text { adequate therapeutic trials } \\
\text { duration of each trial from } 12 \text { to } 16 \text { weeks to } 36 \text { weeks } \\
\text { to } 1 \text { year }\end{array}$ \\
\hline Stage 3 & $\begin{array}{l}\text { failure of } 3 \text { or more adequate therapeutic trials } \\
\text { duration of each trial from } 12 \text { to } 16 \text { weeks to } 36 \text { weeks } \\
\text { to } 1 \text { year }\end{array}$ \\
\hline Stage 4 & $\begin{array}{l}\text { failure of } 3 \text { or more adequate trials including at } \\
\text { least } 1 \text { involving augmentation/combination or } \\
\text { electroconvulsive therapy } \\
\text { duration of each trial at least } 3 \text { months }\end{array}$ \\
\hline
\end{tabular}

Table 4. Staging of bipolar disorder

\begin{tabular}{ll} 
Stage 1 a $\begin{array}{l}\text { mild or nonspecific symptoms of mood disorder/ } \\
\text { prodromal phase (e.g. increased self-confidence, } \\
\text { energy and elated mood, mood swings) }\end{array}$ \\
& b cyclothymia \\
\hline Stage 2 & $\begin{array}{l}\text { acute manifestations of major depressive disorder and } \\
\text { mania/hypomania }\end{array}$ \\
\hline Stage 3 & $\begin{array}{l}\text { residual phase symptoms with marked impairment in } \\
\text { cognition and functioning despite mood-stabilizing } \\
\text { treatment }\end{array}$ \\
\hline Stage 4 & \begin{tabular}{l} 
acute episodes despite mood-stabilizing treatment \\
\hline
\end{tabular}
\end{tabular}

elated mood); (2) hypomania; (3) manic episode without psychotic features, and (4) manic episode with psychotic features.

Over time, several models of bipolar disorder have been proposed. According to McGorry et al. [19, 22, 23] and Berk et al. [64, 65], bipolar disorder begins with an at-risk, asymptomatic period, where a range of risk factors may be operating (stage 0). Thereafter, individuals exhibit mild or nonspecific symptoms (stage 1a) and progress to manifest prodromal symptoms (stage 1b). Prodromal symptoms may then culminate in a first threshold episode of illness (stage 2), more commonly depressive, which may be followed by a first relapse, of either subthreshold (stage $3 \mathrm{a}$ ) or threshold illness (stage $3 \mathrm{~b}$ ), and a subsequent pattern of remission and recurrences (stage 3c). While some individuals may recover syndromally or symptomatically, others may have an unremitting or treatment-refractory course (stage 4). Suggest- ed treatments were family education and drug use education/reduction at all stages; mental health literacy and brief cognitive skills training at stage 0 ; mental health literacy, counseling, problem solving and exercise at stage 1a; CBT, social cognition interventions and neuroprotective agents at stage $1 \mathrm{~b}$; CBT, atypical antipsychotics and vocational rehabilitation at stage 2 ; long-term stabilization at stage 3 , and clozapine, augmentation strategies and assertive community treatment at stage 4 .

This model was recently revised by McNamara et al. [66]. The main difference is that only 3 stages were included; the unremitting/treatment-refractory course was not taken into account and the high-risk condition was placed at stage 1 rather than at stage 0 , meaning that it is part of the illness. As a consequence, stage 2 was characterized by prodromal clinical features and stage 3 by mania.

A different staging model was hypothesized by Kapczinski et al. [67] and included a latent stage, referring to the condition of being at risk for developing bipolar disorder because of a positive family history or mood/anxiety symptoms, and 4 clinical stages. Stage I included euthymia without overt psychiatric symptoms; stage II was characterized by interepisodic symptoms; stage III involved marked cognitive and functional impairment, and at stage IV the cognitive and functional impairment was so severe as to make the patient no longer autonomous. Mood stabilizer monotherapy and psychoeducation were suggested for stage I, pharmacotherapy plus psychotherapy and the treatment of comorbidities for stage II, complex regimens of treatment for stage III and palliative treatment and day care centers for stage IV.

We propose an integrative model of staging (table 4) that acknowledges the lack of evidence supporting the definition of a stage 0 (at risk). Indeed, risk factors and prodromal symptoms are not sufficiently specific and do not necessarily imply evolution toward the illness [44].

Stage 1 is characterized by prodromal symptoms. There is high interindividual variability between patients that does not allow recognition of a specific prodromal phase. However, prodromal symptoms tend to be consistent within the same individual and this allows room for early intervention [44]. Cyclothymic disorder may also represent a precursor of bipolar disorder as well as a formally acknowledged subtype of subthreshold bipolar disorder $[68,69]$. Cyclothymic individuals report short cycles of depression and hypomania that fail to meet the duration criteria for major affective syndromes. The use of an item of the Clinical Interview for Depression [70], reactivity to social environment, was found to character- 
ize the clinical features [69] and response to treatment [71] of cyclothymic disorder.

Stage 2 refers to acute manifestations of major depressive disorder and mania/hypomania, while residual symptoms characterize stage 3 . They might represent persistent illness, that is the original illness continuing in milder form, despite stabilizing treatment, or the phenomena preceding and underlying the acute episode of illness [39]. Common residual symptoms may be behavioral (i.e. being slowed down, late for work, still overactive, more subdued), cognitive (i.e. fear of relapse, low self-esteem, guilt), affective (i.e. irritability, anxiety, sadness, worry, low energy, sleep problems) or social (i.e. feeling distant from others, alienation) [72]. Residual symptoms may develop into a full affective episode despite stabilizing treatment and characterize stage 4 of our model.

There have been a number of suggestions as to stagespecific treatments $[19,22,23,64-67]$. A randomized controlled trial [73], confirmed by studies on psychoeducation [74], demonstrated the feasibility of early intervention aimed at recognizing prodromal symptomatology. Programs for the early detection and control of hypomanic episodes, based on appraisal of individual prodromal symptoms and intermittent use of lithium, have also been described in bipolar disorder [74] and cyclothymia [71].

The presence of residual symptoms at stage 3 connotes a phase of the illness where the value of psychotherapeutic treatment, in addition to pharmacotherapy, may be considerable. There is some evidence that psychotherapeutic approaches in this stage may be more effective than those that are started in the acute manifestation of illness (stage 2) [74], as was found to be the case in unipolar depression [52].

A comment on the implicit concepts built into the staging model of bipolar disorder seems necessary. In clinical medicine it is common to think that the earlier in the progression of a disease a diagnosis occurs, the more likely it is that symptoms will have a benign course. On the basis of this observation, several authors concluded that the earlier the diagnosis is made, the earlier the treatment is initiated and the greater are the chances of a treatment response, which in turn confers a better prognosis [75]. For this reason, a growing body of literature is exploring the possible allegedly neuroprotective effects of psychotropic drugs. However, data supporting this neuroprotection are missing, and psychotropic drugs may be associated with adverse metabolic effects [66] and entail sensitizing effects potentially leading to a malignant course $[60,62]$.

\section{Panic Disorder}

Fava and Kellner [15] described a staging model for panic disorder (PD) with agoraphobia based on the fact that, in a substantial proportion of patients, agoraphobia, hypochondriacal fears and beliefs and generalized anxiety precede the first panic attack. However, for some patients, the first panic attack can apparently occur without conspicuous prodromal symptoms, while anticipatory anxiety, phobic avoidance and hypochondriasis may develop subsequently. For this reason, they also mentioned Sheehan and Sheehan [76], who outlined a different staging process, as follows: stage 1 (subpanic), characterized by panic attacks with limited symptoms; stage 2 (panic); stage 3 (hypochondriasis); stage 4 (single phobia, that is the setting in which panic occurs); stage 5 (social phobia); stage 6 (agoraphobia), and stage 7 (depression).

An updated version of the Fava and Kellner staging model of panic [15] was presented in 2008 [77]. The first step was pre-agoraphobia with predisposing factors, such as health anxiety and anxiety sensitivity, genetic vulnerability, premorbid personality, hypochondriacal fears and beliefs and impaired psychological well-being. The relative weight of these factors may vary from patient to patient and lead to subtle avoidance patterns and ultimately to agoraphobia (stage 2). Thus, panic attacks start. Health anxiety may turn into hypochondriasis and/or disease phobia and/or thanatophobia. Demoralization and/or major depression may occur (stage 3). The duration of PD with agoraphobia can predispose to the development of other psychiatric complications, notably depression. Moreover, agoraphobia may become more severe and hypochondriacal fears and beliefs may be accentuated (stage 4).

Considering the phenomenology of panic attacks, it has been suggested that truly spontaneous attacks, not preceded by anxiety-provoking cognitions, are uncommon. Patients meeting positive criteria for PD tend to suffer from the whole range of anxiety disorders, and a unique relationship with agoraphobia has not been seen. Indeed, other diagnoses (particularly social phobia and generalized anxiety disorder) frequently predate the onset of panic and agoraphobia [77]. If the onset of PD is conceptualized as a stage of development of anxiety disorders (whether agoraphobia or social phobia or generalized anxiety disorder) and hypochondriasis, instead of a specific disease, the diagnostic sharpness is increased and undifferentiated treatment, which may leave substantial areas of nonresponse, can be substituted with stage-guided therapeutic tools [77]. Fava et al. [77] suggested considering the onset of PD as a stage of develop- 
Table 5. Staging of panic disorder

\begin{tabular}{ll}
\hline Stage 1 & $\begin{array}{l}\text { prodromal phase: subclinical symptoms of agorapho- } \\
\text { bia and/or social phobia and/or generalized anxiety } \\
\text { disorder and/or hypochondriasis }\end{array}$ \\
\hline Stage 2 & $\begin{array}{l}\text { acute manifestations of agoraphobia and/or social } \\
\text { phobia and/or generalized anxiety disorder and/or hy- } \\
\text { pochondriasis }\end{array}$ \\
\hline Stage 3 & $\begin{array}{l}\text { panic disorder with worsening of anxiety and hypo- } \\
\text { chondriacal symptoms; demoralization and/or major } \\
\text { depression may occur }\end{array}$ \\
\hline Stage 4 & $\begin{array}{l}\text { chronic panic disorder and agoraphobia and/or social } \\
\text { phobia and/or generalized anxiety disorder and/or hy- } \\
\text { pochondriasis (in attenuated or persistent form); in- } \\
\text { creased liability to major depression }\end{array}$ \\
\hline
\end{tabular}

Table 6. Staging of levels of treatment resistance in panic disorder

\begin{tabular}{ll}
\hline Stage 0 & no history of failure to respond to a therapeutic trial \\
\hline Stage 1 & $\begin{array}{l}\text { failure of at least } 1 \text { adequate therapeutic trial (either } \\
\text { pharmacological or psychological) }\end{array}$ \\
\hline Stage 2 & $\begin{array}{l}\text { failure of at least } 2 \text { adequate therapeutic trials, including } \\
\text { at least } 1 \text { psychological }\end{array}$ \\
\hline Stage 3 & $\begin{array}{l}\text { failure of } 3 \text { or more adequate therapeutic trials, includ- } \\
\text { ing at least } 1 \text { involving psychotherapy }\end{array}$ \\
\hline Stage 4 & $\begin{array}{l}\text { failure of } 3 \text { or more adequate therapeutic (either phar- } \\
\text { macological or psychological) trials, including at least } 1 \\
\text { involving a psychotherapy/pharmacotherapy combina- } \\
\text { tion }\end{array}$ \\
\hline
\end{tabular}

ment of anxiety disorders and hypochondriasis, instead of a specific disease.

The model of PD that is depicted in table 5 has wide support in the literature. An analysis of subclinical symptomatology $[78,79]$ concluded that the most common prodromal symptoms were depressed mood, illness phobia, distress and avoidance of closed spaces, excessive worries, negative affectivity, anxiety sensitivity and health anxiety or fear of disease, whereas frequent residual symptoms were generalized anxiety, somatic anxiety, low self-esteem, agoraphobia, hypochondriasis, reduced psychological and physical well-being, limited symptoms of panic attacks, anticipatory anxiety and depression.

Viewing the longitudinal development of panic according to stages may entail an advantage for monitoring the patient's progress [80]. Because of the chronic nature of $\mathrm{PD}$, the emphasis of treatment has been shifted more and more to the long-term outcome; the disappearance of residual symptoms may become the final target of therapy since they constitute a substantial risk of relapse [79]. This has been clearly outlined in the long-term outcome of patients with PD treated with behavioral interventions [81]. Another interesting proposal could be stage-oriented therapy, which is a specific therapy planned to treat a specific stage of the illness in order to produce additional benefits. Up to now, unfortunately, only a few studies have used the staging model to test pharmacological/psychological intervention efficacy, and none satisfied our inclusion criteria.

Considering that treatment resistance in PD is a growing and emerging issue [82, 83], we here propose staging levels of treatment resistance (table 6). At stage 1, a pharmacological/psychological intervention fails to give benefits; at stage 2, the failure involves 2 different interventions, including at least 1 involving psychotherapeutic treatment; stage 3 involves the failure of 3 or more adequate therapeutic interventions, including at least 1 involving psychotherapy, and at stage 4 there is failure of 3 or more adequate therapeutic trials, including at least 1 combination of psychotherapy and pharmacotherapy.

\section{Substance Use Disorders}

Langenbucher and Chung [84] proposed 3 stages for the development of alcohol use disorders. The first was alcohol abuse, the second dependence and the third accommodation to the illness, consisting of curtailing important activities to drink and spending a great deal of time drinking. Later on, Chung et al. [85] found 4 stages of development of alcohol abuse/dependence. Stage 1 was abuse; stage 2 was what they called 'consequation', that is social, medical and psychological problems and attempts to quit or cut down; stage 3 was accommodation to the illness, and stage 4 was characterized by physiological dependence.

In table 7, we integrate the above models. Stage 1 represents alcohol abuse; stage 2 involves decreased functioning and attempts to cut down; at stage 3 , tolerance is evident and alcohol abuse becomes severe, and finally alcohol dependence occurs (stage 4). Since in this model the stages refer to the DSM diagnosis of alcohol abuse and dependence, the treatments proposed are those included in the more recent guidelines [86, 87], and the staging system for treatment resistance suggested here (table 8 ) is based on their work.

A staging model has also been applied for remission; substance abstinence tends to be an ongoing process from dependence through abuse and misuse, before quitting. Moreover, after remission, prodromal symptoms (e.g. 
substance misuse) tend to become the residual symptomatology which may progress to be prodromal symptoms of relapse. Accordingly, Yeh et al. [88] found that alcoholdependent individuals free themselves of addiction progressively via 3 phases. The first phase was the indulgence, ambivalence and attempt cycle (i.e. the sufferer is trapped in a cycle of attempting to give up and failing). The second phase was the turning point, which included the personal nadir (i.e. they are in despair and afraid of dying) and self-belief and acceptance (i.e. they admit to themselves that they are drunkards and desperate and make a constant effort to remain sober). In the third phase, they embrace the idea of change and self-rescue.

In a study by Favrat et al. [89], a clinically relevant staging system based on patients' characteristics on admission, which accurately predicts adverse outcomes in a methadone maintenance program, was developed. This system was composed of 4 main predictors for treatment retention: quantity of heroin used, history of previous incarceration, previous remand in a reform school and medical illnesses related to heavy drug use.

Motivation to undergo treatment and change behavior has also been submitted to a staging system and may yield valuable insights into the psychological resistance of patients [6]. Prochaska and DiClemente [90-94] developed a seminal example of clinical staging in substance use disorders which is called the transtheoretical model (TTM) of change. This is an integrative and comprehensive model of behavior change [90-94] postulating that people progress through 5 stages when changing behaviors. When they do not recognize that a problem exists and have no intention to change, it is the 'pre-contemplation' stage. The 'contemplation' stage is marked by ambivalence and inaction. In 'preparation/determination', the individual perceives a significant discrepancy between the current and desired status, becoming committed and preparing to change. Implementing a plan to change one's behavior reflects the 'action' stage. Finally, in the 'maintenance' stage, the subject solidifies the new pattern of behavior and focuses on avoiding relapse. Prochaska and Norcross [95] also defined a sixth stage, 'termination', in which the individual has completed the process of change, has a high level of confidence across all high-risk situations and no temptation to relapse. The TTM proposed that individuals move sequentially through the stages but may revert to earlier stages before achieving complete abstinence. It also propounded that incremental moves through the stages, independently of an active attempt to quit, predict higher eventual levels of abstinence [96].
Table 7. Staging of alcohol use disorders

\begin{tabular}{ll}
\hline Stage 1 & prodromal phase: alcohol abuse \\
\hline Stage 2 & $\begin{array}{l}\text { acute manifestations: important activities are cut down } \\
\text { in order to drink, a great deal of time is spent drinking, } \\
\text { several attempts to quit or cut down are undertaken } \\
\text { without success }\end{array}$ \\
\hline Stage 3 & $\begin{array}{l}\text { residual phase: several activities are given up, tolerance } \\
\text { is present and role interference is evident }\end{array}$ \\
\hline Stage 4 & $\begin{array}{l}\text { chronic (in attenuated or persistent form): alcohol de- } \\
\text { pendence }\end{array}$ \\
\hline
\end{tabular}

Table 8. Staging of levels of treatment resistance in alcohol use disorders

\begin{tabular}{ll} 
Stage 0 & no history of failure to respond to therapeutic trial \\
\hline Stage 1 & failure of at least 1 psychological intervention trial \\
\hline Stage 2 & $\begin{array}{l}\text { failure of at least } 2 \text { adequate psychological intervention } \\
\text { trials }\end{array}$ \\
\hline Stage 3 & $\begin{array}{l}\text { failure of } 3 \text { or more psychological intervention trials } \\
\text { and a community-based assisted withdrawal/ } \\
\text { inpatient care }\end{array}$ \\
\hline Stage 4 & $\begin{array}{l}\text { failure of } 3 \text { or more adequate therapeutic (psychologi- } \\
\text { cal or pharmacological intervention) trials including at } \\
\text { least } 1 \text { intensive and structured community-based in- } \\
\text { tervention to prevent relapses }\end{array}$ \\
\hline
\end{tabular}

In 1994, Prochaska et al. [97] successfully tested this model in quitting smoking and in cocaine cessation; thereafter it was applied in opiate addicts [98-100] and in alcohol abuse [101-103].

Notwithstanding the literature suggesting the conceptual validity [104] and the practical usefulness of the TTM (e.g. a standard practice is to set a quit date during smoking cessation on the assumption that abrupt attempts to quit are less likely to succeed) [105-108], serious problems with the TTM have been articulated [104, 109125]. In this context, West [107] pointed out the limits of such a model, proposing instead a new theory, the plans, responses, impulses, motives and evaluations model [107, 108]. Unfortunately, literature on the validity of this new theory and its usefulness in clinical practice is still lacking. Moreover, while replicating the study of Callaghan et al. [126], which did not support the validity of the TTM, Heather et al. [127] obtained different results, and a recent meta-analysis claimed the usefulness of TTM stages of change in predicting important treatment outcome mea- 
Table 9. Staging of anorexia nervosa

\begin{tabular}{ll}
\hline Stage 1 & $\begin{array}{l}\text { prodromal phase: 'uneasiness and fullness' after eating, } \\
\text { reduction of food intake, choice of 'safe' food }\end{array}$ \\
\hline Stage 2 & $\begin{array}{l}\text { acute manifestations: severe restriction, increased activ- } \\
\text { ity levels, complete denial of the illness, growing atten- } \\
\text { tion to body weight/shape/size, social impairment }\end{array}$ \\
\hline Stage 3 & residual phase \\
\hline Stage 4 & $\begin{array}{l}\text { chronic (in attenuated or persistent form): extreme } \\
\text { emaciation, laborious exercise and 'general debility'; } \\
\text { risk of co-occurrence of other psychiatric disorder (e.g. } \\
\text { alcohol use disorder) }\end{array}$ \\
\hline
\end{tabular}

sures [128]. As a consequence, Norcross et al. [128] proposed a brief outline of research-supported therapist behaviors that can enhance treatment outcomes, including, among others, assessment of the stage of change and tailoring of the treatment processes to the stages.

\section{Eating Disorders}

The earliest description of anorexia nervosa (AN) made reference to the concept of stages; Lasegue [129] described a gradual descent into the illness, distinguishing 3 phases in its progression. The first was marked by an 'uneasiness and fullness' after eating with reduction of food intake. The second was characterized by severe restriction, increased activity levels and 'an intellectual perversion' resulting in a complete denial of the illness. The third stage involved extreme emaciation, laborious exercise and 'general debility'. Later on, Halmi [130] considered an acute stage versus a refeeding one, or a chronic and a recovered stage of the illness. Other authors described a progression through stages, with the chronic phase receiving more attention. Klein and Walsh [131] observed that weight loss in AN was usually accomplished primarily through a reduction in food intake, which often progressed through stages. First, all foods that could potentially contain fat were eliminated, and thus only 'safe' foods were consumed. Thinness became an increasingly salient goal, and growing attention was paid to body weight, shape and size. Idiosyncratic rules developed around when, what and how much a person permits herself to eat and around how much exercise was required. At the outset of the disorder, weight loss may be socially reinforced. Under pressure to gain weight, individuals often turned to deception. Not uncommonly, they hide weight loss from family members, social avoidance facilitated progressive weight loss, and alcoholism might occur.

Staging of Mental Disorders
More recently, Maguire et al. [132] proposed a staging model of AN which took into account the severity and duration of the illness.

On the basis of the above literature, we propose in table 9 a staging model for AN. Such a model finds support in the literature, which showed that the course of AN is characterized by high rates of partial recovery and low rates of full recovery [133] and that full remission/recovery is more stable than the stage of partial remission [134].

No indications are available on a stage-oriented use of therapeutic tools, such as psychotherapy [135].

The concept of clinical staging has also been applied to bulimia nervosa (BN). Klein and Walsh [131] suggested that $\mathrm{BN}$ typically begins during or following a diet. At some point, a behavioral method is discovered that promises to rid the body of unwanted calories. Thereafter, initially great satisfaction may be experienced that appealing food may be eaten without weight gain. As the disorder progresses, perceived control over eating diminishes. Inappropriate compensatory behaviors and self-imposed caloric restriction stimulate hunger and binge eating and a vicious cycle develops.

We propose a staging model which takes into account the literature (table 10). Stage 1 is characterized by prodromal symptoms (e.g. anorexia, low self-esteem); at stage 2, the acute episode of illness occurs; it may then leave residual symptoms (stage 3 ) and an attenuated or persistent form of the illness (stage 4). Indeed, Raffi et al. [136] found that BN patients report prodromal symptoms before the onset of the disorder; anorexia, low self-esteem, depressed mood, anhedonia, generalized anxiety and irritability were the most common. Less common were reactivity and phobic avoidance. Thus, subclinical mood disorder, especially if combined with stressful life circumstances, may produce an allostatic load [137-139] which increases the probability of developing BN.

An interesting application of DiClemente and Prochaska's stages of change model occurred in eating disorders. Ward et al. [140] assessed stages of change and processes used to achieve them and found that contemplation and pre-contemplation were the most common stages. The most frequently used processes of change were self-reevaluation, helping relationships and consciousness raising, with different processes predominating at different stages. Blake et al. [141] found that the vast majority of $\mathrm{BN}$ outpatients were in the action stage, whereas the AN outpatients were more distributed across the stages, with half in the pre-contemplation and contemplation stages. Jordan et al. [142] proposed 5 stages in eating disorders: pre-contemplators were not thinking

Psychother Psychosom 2013;82:20-34 
Table 10. Staging of bulimia nervosa

\begin{tabular}{ll}
\hline Stage 1 & $\begin{array}{l}\text { prodromal phase: anorexia, low self-esteem, depressed } \\
\text { mood, anhedonia, generalized anxiety and irritability }\end{array}$ \\
\hline Stage 2 & $\begin{array}{l}\text { acute manifestations: diminished perceived control } \\
\text { over eating, inappropriate compensatory behaviors }\end{array}$ \\
\hline Stage 3 & residual phase \\
\hline Stage 4 & $\begin{array}{l}\text { chronic (in attenuated or persistent form): self-im- } \\
\text { posed caloric restriction stimulates hunger and binge } \\
\text { eating and a vicious cycle develops }\end{array}$ \\
\hline
\end{tabular}

about and not planning to recover from anorexia/bulimia in the following 6 months; contemplators were thinking about trying to recover in 6 months; preparers intended to start trying to recover in 30 days; those in action had been actively recovering from their eating disorder for fewer than 6 months, and those in maintenance had been in active recovery (or recovered) for more than 6 months. They found that stopping restricting/bingeing/purging was the best measure of stage of change for recovery from AN. In contrast, Hasler et al. [143] observed that the stages of change are an independent dimension. Maguire et al. [132] noted that an individual's stage of change is only one marker of the illness within a variety of different disease presentations. An individual can be at severe medical risk as a consequence of $\mathrm{AN}$, yet still present in a highly motivated stage of change.

\section{Discussion}

Clinical psychologists and psychiatrists constantly use staging systems. However, these systems derive from their own clinical experiences and tend to be idiosyncratic. Aside from the severity of the disorder, the clinician may weigh factors such as patients' social support and their adaptation, resilience and reaction to previous conflicts, threats or losses, or the clinician may assess motivation and anticipate compliance with treatment. All of these can influence the choice of treatment and reflect on the prognosis. This diverse assessment might be made among patients who share the same diagnosis. Thus, the clinician tends to use subclassifications within a diagnostic category, some of which contain elements of staging [15].

Staging in most disorders cannot be separated from an evaluation of the patient's premorbid personality and personality traits. After the acute phase of a psychiatric disorder, it may be difficult to assess whether partial or full remission has occurred unless the assessor knew the patient well before the onset of the disorder. Attenuated symptoms may be observed after recovery from a psychiatric disorder, and their nature is sometimes uncertain; the residual symptoms may be caused by a partial persistence of the disorder or an aggravation of a preexisting abnormal personality trait. Such an aggravation may be caused by various factors like, for instance, life events or stressors. Alternatively, it may be a consequence of the psychosocial effects of the recent psychiatric disorder as the effect of allostatic load, or a combination of these factors and others previously discussed [15].

The present systematic review suggests staging models as a proper assessment of the longitudinal development of mental disorders, such as schizophrenia, unipolar depression, bipolar disorder, $\mathrm{PD}$, substance use disorders and eating disorders. Staging differs from the conventional diagnostic practice in that it not only defines the extent of progression of a disorder at a particular point in time but also where a person is currently located along the continuum of the course of illness.

There also appears to be a relationship between residual and prodromal symptomatology. Detre and Jarecki [144] provided a model for relating prodromal and residual symptomatology in psychiatric illness, defined as the rollback phenomenon: as the illness remits, it progressively recapitulates, although in reverse order. Certain prodromal symptoms may be overshadowed by the acute manifestation of the disorder but persist as residual symptoms and progress to become prodromes of relapse. In fact, prodromal symptoms of relapse tend to mirror those of the initial episode [44]. According to the rollback model, there is also a temporal relationship between the time of development of a disorder and the duration of the phase of recovery. This has several exemplifications in clinical medicine. For instance, herpes zoster (chicken pox) has a sudden onset and quick recovery in children, whereas it develops insidiously and tends to have a long residual phase in adults.

Feinstein [145] also remarked that, when making a diagnosis, thoughtful clinicians seldom leap from a clinical manifestation to diagnostic end points. Instead, the clinical reasoning, as well as the clinical judgment, should go through a series of 'transfer stations' where potential connections between presenting symptoms and pathophysiological processes are drawn. The stations are a pause for verification or change to another direction. This strategy particularly applies to psychiatric disorders. An initial state of generalized anxiety may 
assume phobic connotations at some later point in time. If major depression then ensues, mood symptomatology may overshadow the previous anxiety disturbances, but the diagnosis of depression is only a transfer from prodromal to residual anxiety $[6,52]$. Thus, staging is an assessment strategy that allows the clinician to go through the diagnostic transfer stations and formulate clinical reasoning. This clinimetric perspective provides an intellectual home for the reproduction and standardization of clinical intuitions [8].

In 1967, Alvan Feinstein [146] urged clinicians to develop a 'basic science' of their own to study clinical phenomena directly, specify the importance of different types of clinical data, create appropriate systems of taxonomy for classifying the information and develop intellectual models and pragmatic methods that would articulate the clinical process and use the results for quantified analyses. Such a line of research, which affects clinical decision making, has been neglected.

Exclusive reliance on diagnostic criteria has impoverished the clinical process and does not reflect the complex thinking that underlies decisions in psychiatric practice. The use of transfer stations with repeated assessments instead of diagnostic endpoints; the building of global formulations of clinical integration; staging methods, and expansion and better organization of clinical information, encompassing subclinical distress, illness behavior, lifestyle and psychological well-being, may be an antidote to oversimplified models that derive from biological reductionism, neglect individual responses to treatment and clash with clinical reality [6].
There is a need for filtering treatment options with clinical judgment and patient-specific problems that take into account individual staging classifications [147]. This is what actually occurs in clinical practice but it is often dismissed as an expression of highly subjective clinical evaluation [148]. An effective use of staging requires the availability of specific instruments that may increase interrater reliability; however, there have been only limited efforts in this direction $[9,149]$.

According to the present review, clinical staging models are currently available for certain psychiatric disorders, and an increasing body of research supports the existence of stages in the longitudinal development of such disorders. Treatment implications of clinical staging are still not completely clear. Even though many authors claim that clinical staging allows early pharmacological intervention, thus preventing the onset or stopping the development of a psychiatric disorder, there is currently no firm evidence to support such opinion. Since prodromal symptomatology achieves its specificity only in light of the individual history of the patient, its appraisal can only be retrospective and does not lend itself to intervention procedures before the occurrence of the acute manifestations of the disorder.

\section{Disclosure Statement}

Dr. Cosci received a grant from Pfizer in the framework of the Global Research Awards for Nicotine Dependence. Dr. Fava has no conflict of interest to declare. No funding was received by the authors to carry out the present review.

\section{References}

1 American Psychiatric Association: Diagnostic and Statistical Manual of Mental Disorders, ed 4 (DSM-IV). Washington, American Psychiatric Association, 1994.

2 World Health Organisation: ICD-10 Classifications of Mental and Behavioural Disorder: Clinical Descriptions and Diagnostic Guidelines. Geneva, World Health Organisation, 1992.

-3 Batstra L, Frances A: Holding the line against diagnostic inflation in psychiatry. Psychother Psychosom 2012;81:5-10.

4 Raven M, Parry P: Psychotropic marketing practices and problems: implications for DSM-5. J Nerv Ment Dis 2012;200:512-516.

5 Zimmerman M: Symptom severity and guideline based recommendations for depressed patients. Psychother Psychosom 2012;81:329-332.
6 Fava GA, Rafanelli C, Tomba E: The clinical approach process in psychiatry: a clinimetric approach. J Clin Psychiatry 2012;73:177-184.

7 Feinstein AR: The Jones criteria and the challenge of clinimetrics. Circulation 1982; 66:1-5.

8 Fava GA, Tomba E, Sonino N: Clinimetrics: the science of clinical measurements. Int J Clin Pract 2012;66:11-15.

-9 Tomba E, Bech P: Clinimetrics and clinical psychometrics. Psychother Psychosom 2012; 81:333-343.

10 The Criteria Committee of the New York Heart Association: Nomenclature and Criteria for Diagnosis of Diseases of the Heart and Great Vessels, ed 9. Boston, Little, Brown, 1994.
11 Mauch P, Armitage P, Diehl V, Hoppe R, Weiss L: Hodgkin's Disease. Philadelphia, Lippincott Williams \& Wilkins, 1999.

12 Erikson EH: Childhood and Society. New York, Norton, 1963.

13 Piaget J: Piaget's theory; in Mussen PH (ed): Carmichael's Manual of Child Psychology, ed 3. New York, Wiley, 1970, vol I, pp 703732.

14 Fava GA, Kellner R: Prodromal symptoms in affective disorders. Am J Psychiatry 1991; 148:823-830.

15 Fava GA, Kellner R: Staging: a neglected dimension in psychiatric classification. Acta Psychiatr Scand 1993;87:225-230.

16 McGorry PD: Issues for DSM-V: clinical staging: a heuristic pathway to valid nosology and safer, more effective treatment in psychiatry. Am J Psychiatry 2007; 164:859-860. 
17 McGorry PD: Staging in neuropsychiatry: a heuristic model for understanding, prevention and treatment. Neurotox Res 2010;18: 244-255.

18 McGorry PD: Risk syndromes, clinical staging and DSM V: new diagnostic infrastructure for early intervention in psychiatry. Schizophr Res 2010;120:49-53.

-19 McGorry PD, Hickie IB, Yung AR, Pantelis C, Jackson HJ: Clinical staging of psychiatric disorders: a heuristic framework for choosing earlier, safer and more effective interventions. Aust NZ J Psychiatry 2006;40:616622.

20 Yung AR, McGorry PD: The prodromal phase of first-episode psychosis: past and current conceptualizations. Schizophr Bull 1996;22:353-370.

21 Yung AR, McGorry PD: Prediction of psychosis: setting the stage. Br J Psychiatry 2007; 51(suppl):s1-s8.

-22 McGorry PD, Purcell R, Hickie IB, Yung AR, Pantelis C, Jackson HJ: Clinical staging: a heuristic model for psychiatry and youth mental health. Med J Aust 2007;187:S40S42.

-23 McGorry PD, Nelson B, Goldstone S, Yung AR: Clinical staging: a heuristic and practical strategy for new research and better health and social outcomes for psychotic and related mood disorders. Can J Psychiatry 2010;55:486-497.

24 Vieta E, Reinares M, Rosa AR: Staging bipolar disorder. Neurotox Res 2011;19:279-285.

25 Spitzer RL, Endicott J, Robins E: Research Diagnostic Criteria for a Selected Group of Functional Disorders, ed 3. New York, Biometrics Research Division New York State Psychiatric Institute, 1977.

26 Moher D, Liberati A, Tetzlaff J, Altman DG; PRISMA Group: Preferred Reporting Items for Systematic Reviews and Meta-Analyses: the PRISMA Statement. PLoS Med 2009; 6:e1000097.

-27 Lieberman JA, Perkins D, Belger A, Chakos M, Jarskog F, Boteva K, Gilmore J: The early stages of schizophrenia: speculations on pathogenesis, pathophysiology, and therapeutic approaches. Biol Psychiatry 2001;50: 884-897.

28 Agius M, Goh C, Ulhaq S, McGorry P: The staging model in schizophrenia, and its clinical implications. Psychiatr Danub 2010;22: 211-220.

29 Gourzis P, Katrivanou A, Beratis S: Symptomatology of the initial prodromal phase in schizophrenia. Schizophr Bull 2002;28:415429.

30 Herz MI: Toward an integrated approach to the treatment of schizophrenia. Psychother Psychosom 1986;46:45-57.

- 31 Klosterkötter J, Hellmich M, Steinmeyer EM, Schultze-Lutter F: Diagnosing schizophrenia in the initial prodromal phase. Arch Gen Psychiatry 2001;58:158-164.
32 Peralta V, Cuesta MJ: Can schizophrenia be diagnosed in the initial prodromal phase? Arch Gen Psychiatry 2002;59:664-665.

33 Gaebel W, Jänner M, Frommann N, Pietzcker A, Köpcke W, Linden M, Müller P, MüllerSpahn F, Tegeler J: Prodromal states in schizophrenia. Compr Psychiatry 2000;41: 76-85.

34 Marder SR, Wirshing WC, Van Putten T, Mintz J, McKenzie J, Johnston-Cronk K, Lebell M, Liberman RP: Fluphenazine vs placebo supplementation for prodromal signs of relapse in schizophrenia. Arch Gen Psychiatry 1994;51:280-287.

35 Herz MI, Lamberti JS, Mintz J, Scott R, O’Dell SP, McCartan L, Nix G: A program for relapse prevention in schizophrenia: a controlled study. Arch Gen Psychiatry 2000; 57:277-283.

36 Bechdolf A, Schultze-Lutter F, Klosterkötter J: Self-experienced vulnerability, prodromal symptoms and coping strategies preceding schizophrenic and depressive relapses. Eur Psychiatry 2002;17:384-393.

37 Fava GA, Tossani E: Prodromal stage of major depression. Early Interv Psychiatry 2007; 1:9-18.

38 Hetrick SE, Parker AG, Hickie IB, Purcell R, Yung AR, McGorry PD: Early identification and intervention in depressive disorders: towards a clinical staging model. Psychother Psychosom 2008;77:263-270.

39 Paykel ES: Partial remission, residual symptoms, and relapse in depression. Dialogues Clin Neurosci 2008;10:431-435.

40 Eaton WW, Badawi M, Melton B: Prodromes and precursors: epidemiologic data for primary prevention of disorders with slow onset. Am J Psychiatry 1995;152:967-972.

41 Regeer EJ, Krabbendam L, de Graaf R, ten Have M, Nolen WA, van Os J: A prospective study of the transition rates of subthreshold (hypo)mania and depression in the general population. Psychol Med 2006;36:619-627.

42 Fava GA, Grandi S, Zielezny M, Canestrari R, Morphy MA: Cognitive behavioral treatment of residual symptoms in primary major depressive disorder. Am J Psychiatry 1994, 151:1295-1299.

43 Iacoviello BM, Alloy LB, Abramson LY, Choi JY: The early course of depression: a longitudinal investigation of prodromal symptoms and their relation to the symptomatic course of depressive episodes. J Abnorm Psychol 2010;119:459-467.

44 Fava GA: Subclinical symptoms in mood disorders: pathophysiological and therapeutic implications. Psychol Med 1999;29:47-61.

45 Judd LL, Akiskal HS, Maser JD, Zeller PJ, Endicott J, Coryell W, Paulus MP, Kunovac JL, Leon AC, Mueller TI, Rice JA, Keller MB: Major depressive disorder: a prospective study of residual subthreshold depressive symptoms as predictor of rapid relapse. J Affect Disord 1998;50:97-108.
46 Cuijpers P, Smit F: Subthreshold depression as a risk indicator for major depressive disorder: a systematic review of prospective studies. Acta Psychiatr Scand 2004;109:325-331.

47 Taylor DJ, Walters HM, Vittengl JR, Krebaum S, Jarrett RB: Which depressive symptoms remain after response to cognitive therapy of depression and predict relapse and recurrence? J Affect Disord 2010;123: 181-187.

48 Klein DN, Schwartz JE, Rose S, Leader JB: Five-year course and outcome of dysthymic disorder: a prospective, naturalistic followup study. Am J Psychiatry 2000;157:931-939.

49 Klein DN, Shankman SA, Rose S: Ten-year prospective follow-up study of the naturalistic course of dysthymic disorder and double depression. Am J Psychiatry 2006;163:872880 .

50 Fava GA, Grandi S, Zielezny M, Rafanelli C, Canestrari R: Four year outcome for cognitive behavioral treatment of residual symptoms in major depression. Am J Psychiatry 1996;153:945-947.

-51 Fava GA, Ruini C, Rafanelli C, Finos L, Conti S, Grandi S: Six-year outcome of cognitive behavior therapy for prevention of recurrent depression. Am J Psychiatry 2004;161:18721876.

52 Fava GA, Tomba E: New modalities and treatment planning in depression: the sequential approach. CNS Drugs 2010;24:453465 .

53 Thase ME, Rush AJ: When at first you don't succeed: sequential strategies for antidepressant non-responders. J Clin Psychiatry 1997; 58:23-29.

-54 Souery D, Amsterdam J, de Montigny C, Lecrubier Y, Montgomery S, Lipp O, Racagni G, Zohar J, Mendlewicz J: Treatment resistant depression: methodological overview and operational criteria. Eur Neuropsychopharmacol 1999;9:83-91.

55 Fava M: Diagnosis and definition of treatment-resistant depression. Biol Psychiatry 2003;53:649-659.

56 Berlim MT, Turecki G: Definition, assessment, and staging of treatment-resistant refractory major depression: a review of current concepts and methods. Can J Psychiatry 2007;52:46-54

57 Petersen T, Papakostas GI, Posternak MA, Kant A, Guyker WM, Iosifescu DV, Yeung AS, Nierenberg AA, Fava M: Empirical testing of two models for staging antidepressant treatment resistance. J Clin Psychopharmacol 2005;25:336-341.

58 Fekadu A, Wooderson S, Donaldson C, Markopoulou K, Masterson B, Poon L, Cleare AJ: A multidimensional tool to quantify treatment resistance in depression: the Maudsley staging method. J Clin Psychiatry 2009;70: 177-184. 
59 Fekadu A, Wooderson SC, Markopoulou K, Cleare AJ: The Maudsley Staging Method for treatment-resistant depression: prediction of longer-term outcome and persistence of symptoms. J Clin Psychiatry 2009;70:952957.

60 Fava GA, Offidani E: The mechanisms of tolerance in antidepressant action. Prog Neuropsychopharmacol Biol Psychiatry 2011;35: 1593-1602.

61 El-Mallakh RS, Gao Y, Briscoe BT, Roberts RJ: Antidepressant-induced tardive dysphoria. Psychother Psychosom 2011;80:57-59.

62 Chouinard H, Chouinard VA: Atypical antipsychotics. Psychother Psychosom 2008;77: 69-77.

63 Carlson GA, Goodwin FK: The stages of mania. Arch Gen Psychiatry 1973;28:221-228.

64 Berk M, Hallam KT, McGorry PD: The potential utility of a staging model as a course specifier: a bipolar disorder perspective. J Affect Disord 2007;100:279-281.

65 Berk M, Conus P, Lucas N, Hallam K, Malhi GS, Dodd S, Yatham LN, Yung A, McGorry $\mathrm{P}$ : Setting the stage: from prodrome to treatment resistance in bipolar disorder. Bipolar Disord 2007;9:671-678.

-66 McNamara RK, Nandagopal JJ, Strakowski SM, DelBello MP: Preventative strategies for early-onset bipolar disorder: towards a clinical staging model. CNS Drugs 2010;24:983996.

67 Kapczinski F, Dias VV, Kauer-Sant'Anna M, Frey BN, Grassi-Oliveira R, Colom F, Berk $\mathrm{M}$ : Clinical implications of a staging model for bipolar disorders. Expert Rev Neurother 2009;9:957-966.

68 Baldessarini RJ, Vázquez G, Tondo L: Treatment of cyclothymic disorder: commentary. Psychother Psychosom 2011;80:131-135.

-69 Tomba E, Rafanelli C, Grandi S, Guidi J, Fava GA: Clinical configuration of cyclothymic disturbances. J Affect Dis 2012;139:244-249.

70 Guidi J, Fava GA, Bech P, Paykel E: The Clinical Interview for Depression. Psychother Psychosom 2011;80:10-27.

-71 Fava GA, Rafanelli C, Tomba E, Guidi J, Grandi S: The sequential combination of cognitive behavioral treatment and well-being therapy in cyclothymic disorder. Psychother Psychosom 2011;80:136-143.

-72 Keitner GI, Solomon DA, Ryan CE, Miller IW, Mallinger A, Kupfer DJ, Frank E: Prodromal and residual symptoms in bipolar I disorder. Compr Psychiatry 1996;37:362-367.

73 Perry A, Tarrier N, Morriss R, McCarthy E, Limb K: Randomized controlled trial of efficacy of teaching patients with bipolar disorder to identify early symptoms of relapse and obtain treatment. BMJ 1999;318:149153.

74 Tomba E, Fava GA: The sequential combination of pharmacotherapy and psychotherapy in mood disorders. J Contemp Psychother 2009;39:101-109.
75 Berk M, Hallam K, Malhi GS, Henry L, Hasty M, Macneil C, Yucel M, Pantelis C, Murphy B, Vieta E, Dodd S, McGorry PD Evidence and implications for early intervention in bipolar disorder. J Ment Health 2010;19:113-126.

76 Sheehan DV, Sheehan KH: The classification of phobic disorders. Int J Psychiatry Med 1982-1983;12:243-266.

77 Fava GA, Rafanelli C, Tossani E, Grandi S: Agoraphobia is a disease: a tribute to Sir Martin Roth. Psychother Psychosom 2008; 77:133-138.

78 Fava GA, Mangelli L: Subclinical symptoms of panic disorder: new insights into pathophysiology and treatment. Psychother Psychosom 1999;68:281-289.

79 Cosci F: The psychological development of panic disorder: implications for neurobiology and treatment. Rev Bras Psiquiatr 2012; 34:S5-S27.

80 Shear MK, Clark D, Feske U: The road to recovery in panic disorder: response, remission, and relapse. J Clin Psychiatry 1998;59: 4-8.

81 Fava GA, Rafanelli C, Grandi S, Conti S, Ruini C, Mangelli L, Belluardo P: Long-term outcome of panic disorder with agoraphobia treated by exposure. Psychol Med 2001;31: 891-898.

82 Holt RL, Lydiard RB: Management of treatment-resistant panic disorder. Psychiatry (Edgmont) 2007;4:48-59.

83 Sanderson WC, Bruce TJ: Causes and management of treatment-resistant panic disorder and agoraphobia: a survey of expert therapists. Cogn Behav Pract 2007;14:26-35.

84 Langenbucher J, Chung T: Onset and staging of DSM-IV alcohol dependence using mean age and survival-hazard methods. J Abnorm Psychol 1995;104:346-354.

85 Chung N, Langenbucher J, McCrady B, Epstein E, Cook S: Use of survival analyses to examine onset and staging of DSM-IV alcohol symptoms in women. Psychol Addict Behav 2002; 16:236-242.

86 National Institute for Health and Clinical Excellence: Alcohol-use disorders: diagnosis, assessment and management of harmful drinking and alcohol dependence. NICE clinical guideline 115, February 2011. www. nice.org.uk/guidance/CG115.

87 Pilling S, Yesufu-Udechuku A, Taylor C, Drummond C; Guideline Development Group: Diagnosis, assessment, and management of harmful drinking and alcohol dependence: summary of NICE guidance. BMJ 2011;342:d700.

88 Yeh MY, Che HL, Wu SM: An ongoing process: a qualitative study of how the alcoholdependent free themselves of addiction through progressive abstinence. BMC Psychiatry 2009;24:9-76.
89 Favrat B, Rao S, O’Connor PG, Schottenfeld $\mathrm{R}$ : A staging system to predict prognosis among methadone maintenance patients, based on admission characteristics. Subst Abus 2002;23:233-244.

$\$ 90$ Prochaska JO, DiClemente CC: Stages and processes of self-change of smoking: toward an integrative model of change. J Consult Clin Psychol 1983;51:390-395.

91 Prochaska JO, DiClemente CC: The Transtheoretical Approach: Crossing the Traditional Boundaries of Therapy. Homewood, Dow Jones-Irwin, 1984.

92 Prochaska JO, DiClemente CC: Common processes of self-change in smoking, weight control, and psychological distress; in Shiftman S, Wills TA (eds): Coping and Substance Use. San Diego, Academic, 1985, pp 345363.

93 Prochaska JO, DiClemente CC: Toward a comprehensive model of change; in Miller WR, Heather N (eds): Treating Addictive Behaviors: Processes of Change. New York, Plenum, 1986, pp 3-27.

94 Prochaska JO, DiClemente CC: Stages of change in the modification of problem behaviors; in Hersen M, Eisler RM, Miller PM (eds): Progress in Behavior Modification. Newbury Park, Sage, 1992, pp 184-218.

95 Prochaska JO, Norcross JC: Stages of change. Psychother Theor Res Pract Train 2001;38:443-448.

-96 Prochaska JO, Velicer WF, Prochaska JM, Johnson JL: Size, consistency, and stability of stage effects for smoking cessation. Addict Behav 2004;29:207-213.

97 Prochaska JO, Velicer WF, Rossi JS, Goldstein MG, Marcus BH, Rakowski W, Fiore C, Harlow LL, Redding CA, Rosenbloom D, Rossi SR: Stages of change and decisional balance for 12 problem behaviors. Health Psychol 1994;13:39-46.

$\checkmark 98$ Abellanas L, McLellan AT: 'Stage of change' by drug problem in concurrent opioid, cocaine, and cigarette users. J Psychoactive Drugs 1993;25:307-313.

$\$ 99$ Isenhart CE: Motivational subtypes in an inpatient sample of substance abusers. Addict Behav 1994;19:463-475.

100 Tejero A, Trujols J, Hernández E, Perez de los Cobos J, Casas M: Processes of change assessment in heroin addicts following the Prochaska and DiClemente transtheoretical model. Drug Alcohol Depend 1997;47: 31-37.

101 DiClemente CC, Bellino LE, Neavins TM: Motivation for change and alcoholism treatment. Alcohol Res Health 1999;23:8692.

102 Project MATCH Research Group: Project MATCH secondary a priori hypotheses. Addiction 1997;92:1671-1698.

103 Project MATCH Research Group: Matching alcohol treatments to client heterogeneity: Project MATCH three year drinking outcomes. Alcohol Clin Exp Res 1998;22: 1300-1311. 
104 Sutton S: Back to the drawing board? A review of applications of the transtheoretical model to substance use. Addiction 2001;96: $175-186$.

105 Larabie LC: To what extent do smokers plan quit attempts? Tobacco Control 2005; 14 : 425-428.

106 Velicer WF, Friedman RH, Fava JL, Gulliver SB, Keller S, Sun X, Ramelson H, Prochaska JO: Evaluating nicotine replacement therapy and stage-based therapies in a population-based effectiveness trial. J Consult Clin Psychol 2006;74:1162-1172.

107 West R: Time for a change: putting the Transtheoretical (Stages of Change) Model to rest. Addiction 2005; 100:1036-1039.

108 West R: Theory of Addiction. Oxford, Blackwell, 2006.

-109 Bunton R, Baldwin S, Flynn D, Whitelaw J: The 'stages of change' model in health promotion: science and ideology. Crit Public Health 2000; 10:55-70.

110 Etter JF, Perneger TV: A comparison of two measures of stage of change for smoking cessation. Addiction 1999; 94:1881-1889.

- 111 Etter JF, Sutton S: Assessing 'stage of change' in current and former smokers. Addiction 2002;97:1171-1182.

112 Littell JH, Girvin H: Stages of change: a critique. Behav Modif 2002;26:223-273.

113 Whitelaw S, Baldwin S, Bunton R, Flynn D: The status of evidence and outcomes in Stages of Change research. Health Educ Res 2000;15:707-718.

-114 Aveyard P, Massey L, Parsons A, Manaseki S, Griffin C: The effect of Transtheoretical Model based interventions on smoking cessation. Soc Sci Med 2009;68:397-403.

-115 Bridle C, Riemsma RP, Pattenden J, Sowden AJ, Mather L, Watt IS, Walker A: Systematic review of the effectiveness of health behavior interventions based on the transtheoretical model. Psychol Health 2005;20: 283-301.

116 Callaghan RC, Herzog TA: The relation between processes-of-change and stage-transition in smoking behavior: a two-year longitudinal test of the Transtheoretical Model. Addict Behav 2006;31:1331-1345.

-117 Froelicher ES, Kozuki Y: Theoretical applications of smoking cessation interventions to individuals with medical conditions: women's initiative for nonsmoking (WINS) - Part III. Int J Nurs Stud 2002;39:1-15.

-118 Herzog TA: Analyzing the transtheoretical model using the framework of Weinstein, Rothman, and Sutton (1998): the example of smoking cessation. Health Psychol 2008; 27:548-556.

$>119$ Herzog TA: A welcomed and overdue debate. Health Psychol 2010;29:102-103.
120 Riemsma RP, Pattenden J, Bridle C, Sowden AJ, Mather L, Watt IS, Walker A: Systematic review of the effectiveness of stage based interventions to promote smoking cessation. BMJ 2003;326:1175-1177.

121 Spencer L, Pagell F, Hallion ME, Adams TB: Applying the transtheoretical model to tobacco cessation and prevention: a review of literature. Am J Health Promot 2002;17: 7-71.

122 van Sluijs EMF, van Poppel MNM, vanMechelen W: Stage based lifestyle interventions in primary care - are they effective? Am J Prev Med 2004;26:330-343.

123 Webb TL, Sheeran P: Does changing behavioral intentions engender behavior change? A meta-analysis of the experimental evidence. Psychol Bull 2006;132:249-268.

124 Cahill K, Lancaster T, Green N: Stage-based interventions for smoking cessation. Cochrane Database Syst Rev 2010; 10:CD004492.

125 Callaghan RC, Taylor L, Moore BA, Jungerman FS, Vilela FA, Budney AJ: Recovery and URICA stage-of-change scores in three marijuana treatment studies. J Subst Abuse Treat 2008;35:419-426.

126 Callaghan RC, Taykor L, Cunningham JA: Does progressive stage transition mean getting better? A test of the Transtheoretical Model in alcoholism recovery. Addiction 2007;102:1588-1596.

127 Heather N, Hönekopp J, Smailes D; UKATT Research Team: Progressive stage transition does mean getting better: a further test of the Transtheoretical Model in recovery from alcohol problems. Addiction 2009; 104:949-958.

128 Norcross JC, Krebs PM, Prochaska JO: Stages of change. J Clin Psychol 2011;67: 143-154.

129 Lasegue CH: De l'anorexie isterique (translated as: On hysterical anorexia), 1873; in Kaufman H, Harmen M (eds): Evolution of a Psychosomatic Concept: Anorexia Nervosa. New York, International Universities Press, 1964, pp 141-155.

130 Halmi KA: Anorexia nervosa and bulimia. Annu Rev Med 1987;38:373-380.

131 Klein DA, Walsh BT: Eating disorders: clinical features and pathophysiology. Physiol Behav 2004;81:359-374.

$>132$ Maguire S, Le Grange D, Surgenor L, Marks P, Lacey H, Touyz S: Staging anorexia nervosa: conceptualizing illness severity. Early Interv Psychiatry 2008;2:3-10.

133 Herzog DB, Dorer DJ, Keel PK, Selwyn SE, Ekeblad ER, Flores AT, Greenwood DN, Burwell RA, Keller MB: Recovery and relapse in anorexia and bulimia nervosa: a 7.5-year follow-up study. J Am Acad Child Adolesc Psychiatry 1999;38:829-837.
134 Kordy H, Krämer B, Palmer RL, Papezova H, Pellet J, Richard M, Treasure J: Remission, recovery, relapse, and recurrence in eating disorders: conceptualization and illustration of a validation strategy. J Clin Psychol 2002;58:833-846.

135 Hartmann A, Weber S, Herpertz S, Zeeck A; German Treatment Guideline Group for Anorexia nervosa: Psychological treatment for anorexia nervosa. Psychother Psychosom 2011;80:216-226.

136 Raffi AR, Rondini M, Grandi S, Fava GA: Life events and prodromal symptoms in bulimia nervosa. Psychol Med 2000;30: 727-731

137 Fava GA, Guidi J, Semprini F, Tomba E, Sonino N: Clinical assessment of allostatic load and clinimetric criteria. Psychother

Psychosom 2010;79:280-284.
Tomba E, Offidani E: A clinimetric evaluation of the allostatic load in the general population. Psychother Psychosom 2012;81: 378-379.

139 Porcelli P, Laera D, Mastrangelo D, Di Masi A: Prevalence of allostatic overload in patients with chronic cardiovascular disease. Psychother Psychosom 2012;81:375-377.

140 Ward A, Troop N, Todd G, Treasure J: To change or not to change - 'how' is the question? Br J Med Psychol 1996;69:139-146.

141 Blake W, Turnbull S, Treasure J: Stages and processes of change in eating disorders: implications for therapy. Clin Psychol Psychother 1997;4:186:191.

142 Jordan PJ, Redding CA, Troop NA, Treasure J, Serpell L: Developing a stage of change measure for assessing recovery from anorexia nervosa. Eat Behav 2003;3: 365-385.

143 Hasler G, Delsignore A, Milos G, Buddeberg C, Schnyder U: Application of Prochaska's transtheoretical model of change to patients with eating disorders. J Psychosom Res 2004;57:67-72.

144 Detre TP, Jarecki H: Modern Psychiatric Treatment. Philadelphia, Lippincott, 1971.

145 Feinstein AR: An analysis of diagnostic reasoning. I. The domains and disorders of clinical macrobiology. Yale J Biol Med 1973; 46:212-232.

146 Feinstein AR: Clinical Judgment. Baltimore, Williams \& Wilkins, 1967.

147 Tomba E, Fava GA: Treatment selection in depression: the role of clinical judgment. Psychiatr Clin N Am 2012;35:87-98.

148 Fava GA: Clinical judgment in psychiatry: requiem or reveille? Nord J Psychiatry 2012, E-pub ahead of print.

149 Bilsbury CD, Richman A: A staging approach to measuring patient-centred subjective outcomes. Acta Psychiatr Scand 2002;106:5-40. 